\title{
An extended model to predict the compressive, tensile and flexural strengths of HPFRCs and UHPFRCs: definition and experimental validation
}

\author{
V. Savino ${ }^{\mathrm{a}}$, L. Lanzoni ${ }^{\mathrm{b}, \mathrm{c}}$, A.M. Tarantino ${ }^{\mathrm{c}}$, M. Viviani $^{\mathrm{a}}$ \\ ${ }^{a}$ HES-SO / HEIG-VD - Haute Ecole d'Ingénierie et de Gestion du Canton de Vaud, \\ Route de Cheseaux 1, CH-1401 Yverdon \\ ${ }^{b}$ DESD - Dipartimento di Economia, Scienze e Diritto, University of San Marino, Salita \\ alla Rocca 44, Republic of San Marino, 47890 San Marino \\ ${ }^{c}$ DIEF-Department of Engineering "Enzo Ferrari", University of Modena and Reggio \\ Emilia, 41125 Modena, Italy
}

\begin{abstract}
High manufacturing costs of UHPFRC and expensive and time-consuming tests performed to understand the mechanical response under loading restrict still its wider applications in the field of the structural engineering. Predictive models can be useful to reduce the number of requested tests and to optimize the amount of compounds of the mixture, for example detecting the minimal dosage of fibers necessary to attain a given tensile strength and toughness as well. Currently, not many predictive models do exist and one of the most recent, developed in order to estimate the compressive and tensile responses of HPFRCs, was not notably suitable for UHPFRCs. The main purpose of this work concerns the extension of such a model, in order to predict the mechanical response (in flexion as well) of a given HPFRC/UHPFRC for any change of matrix and fiber properties. Theoretical results were compared with experimental data, thus confirming some shortcomings of the previous model. Once the matrix and fiber properties of a marked UHPFRC were selected, the extended model was used to predict the tensile and flexural bending responses of a full scale UHPFRC structural beam, showing good agreement with the experimental results.
\end{abstract}

Keywords: Metal-matrix composites; Mechanical properties; Damage

Email address: luca.lanzoni@unimo.it (L. Lanzoni) 
mechanics; Mechanical testing

\section{Introduction}

Available technical guides and professional recommendations define the Ultra-High-Performance-Concrete (UHPC) in different ways [53, 54, 56, 55]. However, the mechanical behavior of UHPFRCs in tension can be strainsoftening or strain-hardening, according to the product features [28]. Many researchers have discovered the main parameters influencing such a mechanical response [16]. Matrix properties are highly dependent on various factors such as the dosage of fine mineral admixtures [4, 34, 41, 46], size of aggregates [6, 25, 31], size effect of the specimen [1, 18, 29], curing condition [19, 50] and rate of loading [14, 15]. Not less important is the water-to-binder ratio that strongly affects the classical high strength and the flow-able characteristic of the UHPC matrix with the presence of steel fibers [54, 56]. Other researches also focused on fiber properties that mostly affecting the mechanical response in tension of UHPFRC: The fiber shape is closely related to the magnitude of the post-cracking strain capacity of UHPFRC. Previous studies showed the difference in magnitude of pullout strength when the shape of fibers changes [43. A comparison of results by using straight and deformed fibers highlighted that hooked-end and twisted steel fibers achieve a maximum fiber stress three times higher than straight steel fibers, as also confirmed in [42]. The aspect ratio $l / d_{e}\left(l=\right.$ length of fiber, $d_{e}=$ equivalent diameter) also largely influences the post-cracking behavior of UHPFRC. Adding steel fibers with a high $l / d_{e}$ (97.5), [47] improved the fracture energy of about $35 \%$ and $121 \%$ as compared to fibers of medium (81.5) and low (65) $l / d_{e}$, respectively. This effect is mainly due to the increase of the bonding area between the matrix and fibers, leading to higher pullout load carrying capacity. In 42 by increasing the Volume Fraction of fibers embedded within the UHPC $\left(V_{f}\right)$ from 1.5 to $2.5 \%$, both tensile strength and strain capacity were improved of about two times. Other works have been conducted to evaluate how the fiber orientation influences the mechanical response of UHPFRC, e.g. [2, 47]. In [13] was shown that a properly designed casting

\footnotetext{
${ }^{1}$ Recent studies about the mechanical performances of fabric-reinforced cementitious matrix composites can be found in [11, 12, 30, 38, whereas an application of a polymerbased mortar for retrofitting has been reported in 20].
} 
placement should improve the fiber orientation, leading to better tensile performances. For horizontal placements the viscosity of the fluid mixture and the wall effect 26] cause almost all fibers to be aligned perpendicularly to the pouring direction [3] and parallel to its flow in the molding [44].

Few authors attempted to take into account some of properties discussed above in order to accurately predict the compressive and tensile splitting strengths of a given FRC, e.g. 33, 39, 45. The work of [35] focused both to predict the tensile strength by uniaxial tests, being more realistic than splitting tests, and to improve the reliability of previous models extending the investigation towards more types of fibers and dosages. Despite the good results, its application was limited to the fact that only one type of matrix was investigated, confirming its reliability only for concretes with the same strength range (HPFRC). The present work aims at extending the model proposed in [35] in order to predict the compressive and the uniaxial tensile strengths for any HPFRC/UHPFRC as matrix and fiber properties change. The extended model can also estimate the toughness magnitude under flexural bending stress conditions. Its reliability will be discussed by predicting the mechanical performances of a full scale structural beam.

The present work is organized as follows: a description about the materials and test methods adopted in the experimental program are provided in Section 2 , in Section 3 the most relevant results of the experimental investigation are highlighted; the extended model is presented in Section 4 ; conclusions are drawn in Section 5 .

\section{Experimental program}

The empirical previous model developed in [35] was here extended in order to predict the compressive, tensile and flexural bending strengths of a given HPFRC/UHPFRC for any change of matrix and fiber properties. Experimental data of strength tests recorded on both marked UHPFRC (labeled hereafter UHPFRC-A) and marked HPC series - investigated in [35]by varying fiber properties, were taken into account for this purpose. In order to confirm the reliability of the extended model, the mechanical performance of a marked UHPFRC full scale structural beam (labeled hereafter UHPFRC-B) was evaluated and compared with the model prediction. 


\subsection{Materials}

Four types of steel fibers, different in shape (straight and hooked-end) and aspect ratio $l / d_{e}(65,75$ and 85$)$, as illustrated in Fig, 1 , were selected in order to reinforce the UHPC-A matrix and realize several series of specimens. Four different volume fractions $V_{f}$ were treated for each kind of fiber investigated, i.e. 0, 1.5, 2 and 3\%. Dosages higher than $3 \%$ caused fiber balling in the fresh mixture. Each series was composed of three standard $100 \times 100 \times 100 \mathrm{~mm}$ cubes and three dog-bone-shaped specimens, whose geometry is illustrated in Fig 2, of matrix reinforced with a given type of fibers and dosage. For example, the specimens in the first series contain straight fibers with $l / d_{e}$ of 65 and $V_{f}$ of $1.5 \%$. Each series is labeled according to the shape of the studied fiber, $l / d_{e}$, and $V_{f}$. SF and HF stand for straight fiber and hooked fiber; $65,75,85$ represent the $l / d_{e}$ ratio; $1.5,2,3$ are the $V_{f}$ values. Also a series of specimens without fibers was made as control.

A full scale structural $80 \times 1000 \times 10000 \mathrm{~mm}$ beam of UHPFRC-B was cast in-situ. No thermal treatment was applied after casting. The beam was kept in the molds for at least 20 hours then was demolded, protected with plastic sheets and kept inside the precasting plant until 28 days. Six $80 \times 100 \times 500$ $\mathrm{mm}$ long beams and six $\varnothing 50 \times 200 \mathrm{~mm}$ cores specimens were drilled from the structure in order to test the uniaxial tensile and bending flexural strengths. The geometry of the full scale beam and the position of the drilled specimens are illustrated in Fig. 3. As control, a UHPFRC-B series of $100 \times 100 \times 100$ $\mathrm{mm}$ cube and dog-bone shaped specimens were made in lab according to standard conditions. A series of specimens without fibers was also made.

In order to understand the scatter in strength between cores and cast (cylinder) specimens a proper study is discussed afterwards, by using a marked UHPFRC (labeled hereafter UHPFRC-C), see Table 1.

The mix design of UHPFRCs here investigated was provided by the manufacturer (Table 2), even though for UHPFRC-A series different kinds of fibers and dosages were investigated. Typically, marked UHPFRCs include an optimized gradation of granular matter to obtain a high packing density. A high intensity mixer was used to ensure the mix homogeneity. The fibers were inserted in the mix in order to obtain a good dispersion and minimizing the risk of fiber balling. The specimens were made and cured in compliance to the European standards [58]. 

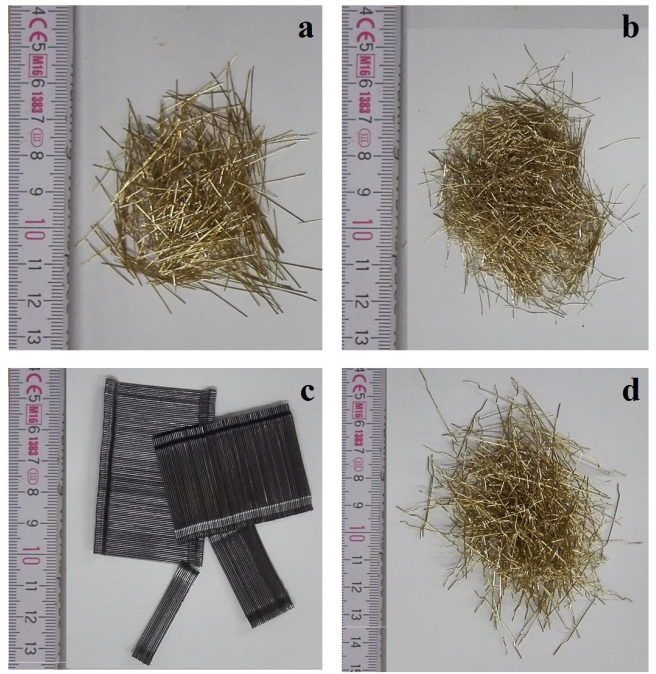

Figure 1: Types of steel fibers investigated: a) SF65; b) SF75; c) HF65; d) HF85

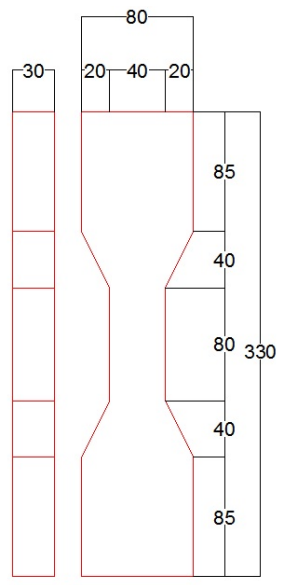

Figure 2: Geometrical dimensions $(\mathrm{mm})$ of the standard dog-bone shaped specimen according to 51 ]

\subsection{Test set-up}

The amount of fibers within the UHPFRC-A (cubic and dog-bone-shaped) specimens was investigated by measuring the hardened-state density in all series according to [60]. Standard uniaxial tensile tests on dog-bone-shaped and cores and standard four-point flexural bending tests on the beams drilled from the full scale structure were performed by using a machine Walter Bay 


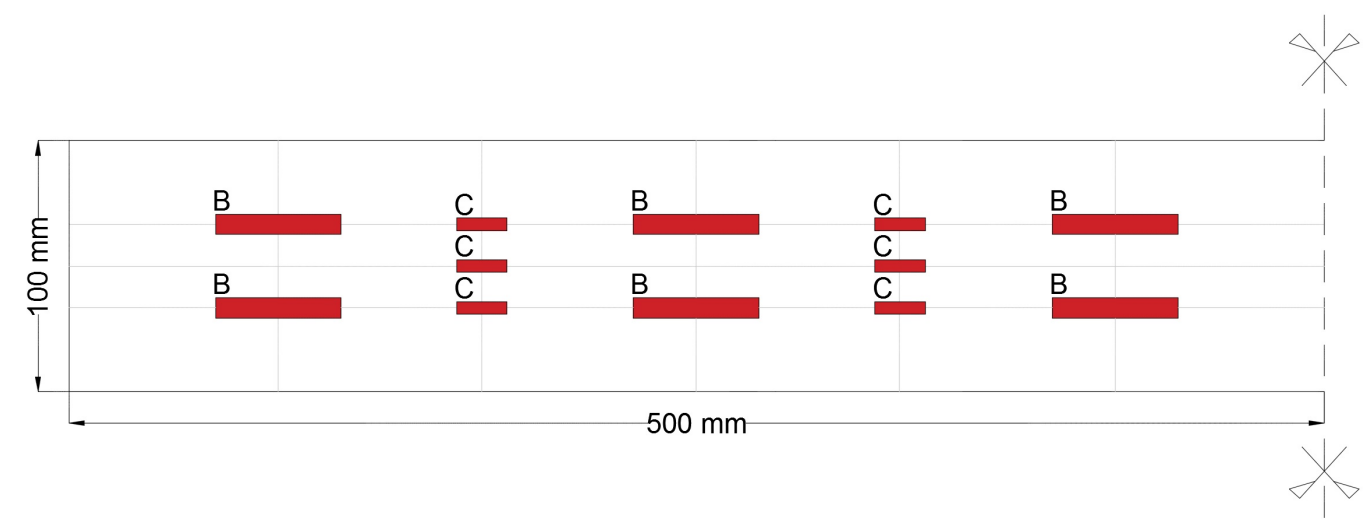

Figure 3: Geometry of the full scale beam and position of the drilled specimens (B: beams, C: cores)

\begin{tabular}{lcccccccccccc}
\hline $\begin{array}{l}\text { UHPFRC } \\
\text { series }\end{array}$ & cube & $\begin{array}{c}\text { dog-bone } \\
\text { /cylinder }\end{array}$ & cores & $\begin{array}{c}\text { drilled } \\
\text { beam }\end{array}$ & $\begin{array}{c}V_{f} \\
\%\end{array}$ & $\begin{array}{c}l \\
\mathrm{~mm}\end{array}$ & $\begin{array}{c}d_{e} \\
\mathrm{~mm}\end{array}$ & $\begin{array}{l}l / d_{e} \\
\text { density } \\
\mathrm{kg} / \mathrm{m}^{3}\end{array}$ & \multicolumn{2}{c}{$\begin{array}{c}\text { weight } \\
\mathrm{kg}\end{array}$} & \multicolumn{2}{c}{$\begin{array}{c}\text { Yield strength } \\
\mathrm{MPa}\end{array}$} \\
\hline A_Control & 3 & 3 & - & - & 0 & - & - & - & - & - & - \\
A_SF65_1.5 & 3 & 3 & - & - & 1.5 & 20 & 0.3 & 65 & 7850 & $1.11 x 10^{-5}$ & 1200 \\
A_SF65_2 & 3 & 3 & - & - & 2 & 20 & 0.3 & 65 & 7850 & $1.11 x 10^{-5}$ & 1200 \\
A_SF65_3 & 3 & 3 & - & - & 3 & 20 & 0.3 & 65 & 7850 & $1.11 x 10^{-5}$ & 1200 \\
A_SF75_1.5 & 3 & 3 & - & - & 1.5 & 13 & 0.175 & 75 & 7850 & $2.45 x 10^{-6}$ & 1250 \\
A_SF75_2 & 3 & 3 & - & - & 2 & 13 & 0.175 & 75 & 7850 & $2.45 x 10^{-6}$ & 1250 \\
A_SF75_3 & 3 & 3 & - & - & 3 & 13 & 0.175 & 75 & 7850 & $2.45 x 10^{-6}$ & 1250 \\
A_HF65_1.5 & 3 & 3 & - & - & 1.5 & 35 & 0.55 & 65 & 7860 & $6.54 x 10^{-5}$ & 1200 \\
A_HF65_2 & 3 & 3 & - & - & 2 & 35 & 0.55 & 65 & 7860 & $6.54 x 10^{-5}$ & 1200 \\
A_HF65_3 & 3 & 3 & - & - & 3 & 35 & 0.55 & 65 & 7860 & $6.54 x 10^{-5}$ & 1200 \\
A_HF85_1.5 & 3 & 3 & - & - & 1.5 & 30 & 0.35 & 85 & 7850 & $2.27 x 10^{-5}$ & 1000 \\
A_HF85_2 & 3 & 3 & - & - & 2 & 30 & 0.35 & 85 & 7850 & $2.27 x 10^{-5}$ & 1000 \\
A_HF85_3 & 3 & 3 & - & - & 3 & 30 & 0.35 & 85 & 7850 & $2.27 x 10^{-5}$ & 1000 \\
B_Control & 3 & 3 & - & - & 0 & - & - & - & - & - & - \\
B_SF65_2.5 & 3 & 3 & 6 & 6 & 2.5 & 20 & 0.3 & 65 & 7850 & $1.11 x 10^{-5}$ & 1200 \\
C_SF130_0.6 & - & 18 & 6 & - & 0.6 & 20 & 0.15 & 130 & 7850 & $2.77 x 10^{-6}$ & 1250 \\
\hline
\end{tabular}

Table 1: Specimens parameters

\begin{tabular}{lccc}
\hline & & $\mathrm{kg}$ in $1 \mathrm{~m}^{3}$ of composite \\
Compounds & UHPFRC-A & UHPFRC-B & UHPFRC-C \\
\hline Premix (cement, silica fume, quartz sable) & 1970 & 2296 & 2183 \\
Superplasticizer & 39 & 51.5 & 25.4 \\
Water & 195 & 204 & 185 \\
Straight steel fibers $13 / 0.175 \mathrm{~mm}$ & $296(3.8 \%)$ & - & - \\
Straight steel fibers $20 / 0.3 \mathrm{~mm}$ & - & $200(2.5 \%)$ & - \\
Straight steel fibers $20 / 0.15 \mathrm{~mm}$ & - & - & $50(0.6 \%)$ \\
\hline
\end{tabular}

Table 2: Mix design 
type LVF-200 kN, according to [51] and [57], respectively. The axial characteristic length of the strain gauge was $100 \mathrm{~mm}$ for all specimens. The axial elongation rate was set at $0.05 \pm 0.01 \mathrm{~mm} / \mathrm{min}$. The end sides of the dog-bone-shaped specimens were larger than the central part, thus allowing the clamps of the machine to easily hold them during the test and to ensure that the failure occurs in the central zone. The compressive tests on cube and cylinder specimens were carried out by using a machine Perrier type $138-5000 \mathrm{kN}$, according to the [59]; the loading rate was $0.6 \mathrm{MPa} / \mathrm{s}$. After testing, UHPFRC-A specimens were cut near to the cracking section for a visual examination of the fibers orientation and distribution.

\section{Results and discussions}

\subsection{Distribution and orientation of fibers (UHPFRC-A series)}

Even though the procedures of mixing, fiber dispersion and casting were the same for all specimen series, the fresh mixture of HF85 series showed a phenomenon of fiber balling, see Fig. 4. It is worth noting that fiber balling affects the mechanical strength of the hardened UHPFRC as well and it creates honeycombs reducing the quality of the UHPFRC even in large scale production. These problems are magnified if an inappropriate mixer is used. Consequently HF85 series had to be discarded from the investigation. The use of special mixers and/or a proper selection of fiber type and volume fractions could permit to avoid the fiber balling. A conventional approach is to use multiple fibers bonded together with water-soluble adhesive [5]. This solution was adopted by replacing HF85 with such a kind of fibers ( $\mathrm{HF}$ 65). By a visual examination at the mixing, the vertical pouring of the fresh mixture into dog-bone-shaped molds promoted a certain level of orientation of fibers along the main axis of the specimen. This phenomenon, promoted by shear stresses, arises due both the high viscosity of the fresh mixture and the wall effect of the mold $[26]^{2}$. The fiber orientation is promoted by the wall effect that, together with the complex geometry of the dog-bone shaped mold, tends to slightly reduce the $V_{f}$ of the fiber in the specimens. In fact, by measuring the hardened-state density in each series it was found that the average density of dog-bone shaped specimens (labeled D in Fig.5a) was slightly lower than cubic specimens (labeled C) for all dosages, as also

\footnotetext{
${ }^{2}$ Viscoelastic effects in reinforced concrete structure have been accounted e.g. in [7, 8, 9].
} 
observed in [35]. The cubic molds were filled vertically, therefore an isotropic and homogenous distribution of fiber was expected. After testing, dog-boneshaped specimens were cut near to the failure sections showing a preferential orientation of fibers. In cubic specimens the fibers were aligned mainly in horizontal planes and perpendicular to the loading force/pouring direction, see Fig.5b.

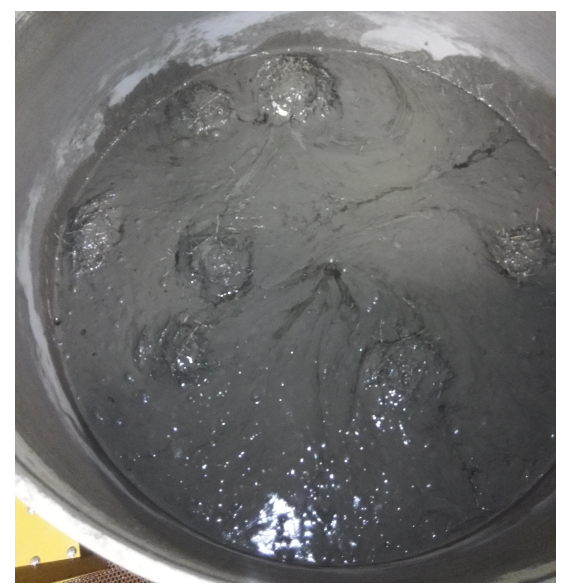

Figure 4: Phenomenon of fiber balling occurred in HF85 series
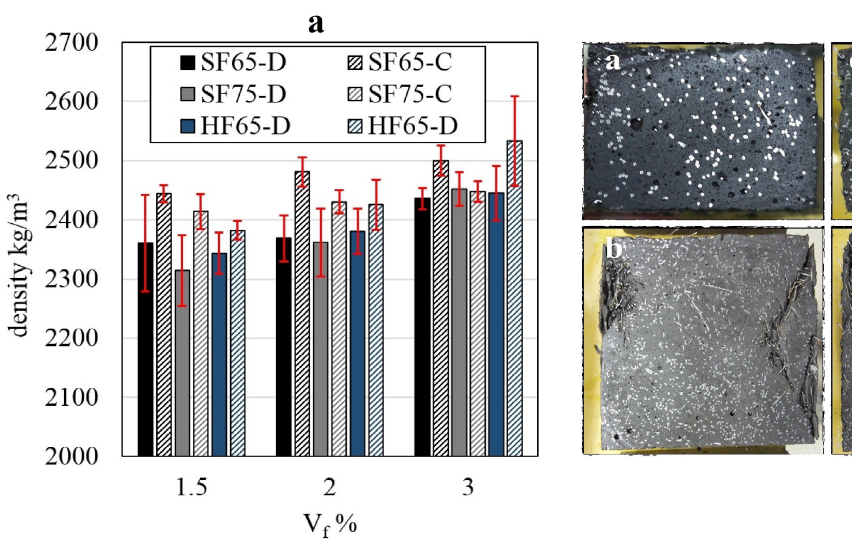

b

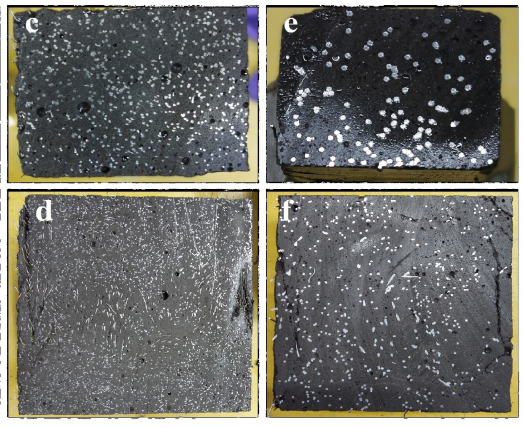

Figure 5: (a)Comparison of the specimens density; (b)Visual orientation and distribution of fibers in series a) SF65-D, b) SF65-C, c) SF75-D, d) SF75-C, e) HF65-D, f) HF65-C (b) 


\subsection{Influence of fibers on compressive strength (UHPFRC-A series)}

It is observed that fibers increased the compressive strength $f_{c}$ until $39 \%$ as both $l / d_{e}$ and $V_{f}$ increased, even though the magnitude is different for each kind of fiber and dosage. In certain works, it was observed that the compressive strength is not affected significantly by the fiber presence, e.g. [49] et. al. Nevertheless the compressive strength is also strongly influenced by the homogeneity of the fiber dispersion that can be achieved by detecting the optimum fiber dosage or a range of optimum fibers dosages. In [48] an increase of compressive strength was observed up to a fiber dosage of $3 \%$. In 32 the investigated UHPFRC recorded the highest compressive strength with a fiber dosage of $2 \%$, whereas in [50] the compressive strength continuously increased with an increase of fiber dosage until to $4 \%$. Similar results were also observed in [10]. This behavior has been observed in this investigation as well. In particular, SF75 series showed a higher increase of strength (up to 39\%) compared to SF65 series (up to 30\%), as $V_{f}$ increases. For fibers with same aspect ratio, HF series showed lower increase of strength, compared to SF series, for low $V_{f}(1.5 \%)$. As $V_{f}$ increases, HF series involves higher gain of strength, see Fig 11. Further details are drawn in Table 3. Since dosages of fibers higher than $3 \%$ caused problems of both balling and workability in the mix, $V_{f}=3 \%$ is considered the upper limit for achieving the best mechanical performances of such a UHPFRC. For all series the favorable orientation of fibers within the mixture permitted to gain toughness, well counteracting the opening cracks.

\subsection{Influence of fibers on uniaxial tensile response (UHPFRC-A series)}

The mechanical response under uniaxial tension is generally subdivided into three phases. Tensile strength tests carried out in the investigation showed a classical three-linear behavior, see Fig,6, with a linear elastic branch maintained up to $90-95 \%$ of the cracking strength, a phase of multi-cracking of the matrix and, finally, a softening behavior due to the debonding between fibers and matrix until a residual strength $f_{r t}$ is reached. The tensile strength $f_{t}$ was reached for uniaxial strain values of about $0.015 \%$, for all series. $f_{t, \text { matrix }}$ value was 6.1 MPa. Instead, for series SF65, SF75, HF65 the maximum and minimum $f_{t}$ values were 9.79, 7.95, 7.62 and 6.96, 5.71, 6.13 $\mathrm{MPa}$, respectively. The ratio $f_{t} / f_{t, \text { matrix }}$ reached about $160 \%$. For all series, $f_{t}$ increased with increasing $V_{f}$ until the upper limit of $3 \%$ was reached. Before first cracking occurs, the stress-strain behavior was not significantly influenced by the shape of tested fibers, even though the higher number of straight 


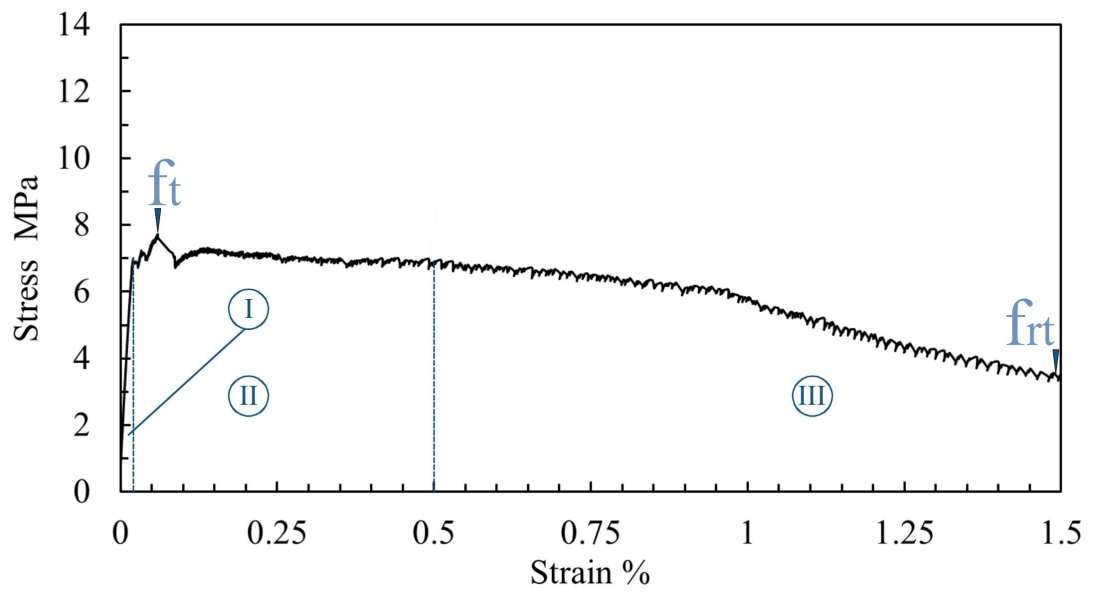

Figure 6: Parameters of the uniaxial tensile behavior recorded from tested dog-bone shaped specimens

fibers in the cross-section, as compared to HF series, led to larger increasing of the first cracking strength, see Table 3. Fibers were mainly oriented along the main axis of the dog-bone-shaped specimen, see 3.1, which perpendicularly to the crack planes conferred gain of toughness in post-cracking. After the matrix crack initiation, the stress was absorbed by the fibers bridging the cracks. Whereas the strain of straight fibers causes the debonding from the matrix and consequently a total pull out, in the case of hooked-end fibers debonding is preceded by the straightening of hooked-ends that retains the fiber from being pulled out, thus extending the energy-absorbing capability (Part II in Fig 6). However, the magnitude of toughness also depends on both fiber size and amount of fibers bridging the crack plane. In the investigated series, for a given $V_{f}$, the number of hooked-end fibers bridging the cracking section was lower compared to one of the straight fibers series because the size of hooked-end fiber was bigger, see Fig.5b. As explained before, it was observed that SF series showed also better post-cracking branches than HF series, highlighting the key role of fiber size and their amount. The residual strength $f_{r t}$ is here defined as the yield strength corresponding to $1.5 \%$ of axial strain. For series SF65, SF75, HF65 the maximum and minimum $f_{r t}$ values were 4.24, 2.01, 1.83 and 2.24, 1.5, 0.97 MPa, respectively (see Fig.11). 


\subsection{Mechanical strength of full scale structural beam and influence of coring} (UHPFRC-B series)

Experimental graphs recorded by uniaxial tensile and flexural bending tests on UHPFRC-B specimens were reported in Fig.7. The average $f_{t}$ of cores was of 8.6 MPa, about $25 \%$ lower than the values recorded for dogbone shaped specimens (11.42 MPa). Also the toughness was lower. This difference can be ascribed to the fact that the in cast specimens the molds shape encouraged a certain degree of fibers orientation, while in the cores drilled from the full scale structural beam fibers were randomly oriented. Also the fact that cores extraction and conditioning promote a certain degree of damage on the specimens may have influenced this result ${ }^{3}$. An investigation concerning such a phenomenon is reported in Section 3.5.

\subsection{Performance comparison between cast and cored specimens (UHPFRC- $C$ series)}

A study on the loss of compressive strength on cores was conducted in an UHPFRC (labeled UHPFRC-C) designed for precast non-structural elements. The mix design is listed in Table 2, 15 cylinders $\varnothing 110 \times 220 \mathrm{~mm}$ were cast along with three $\varnothing 100 \times 200 \mathrm{~mm}$ cylinders and a $200 \times 210 \times 600$ $\mathrm{mm}$ beam. The beam was further instrumented with two fiber optic sensors placed parallel to the shorter side of the mold at a distance of $52 \mathrm{~mm}$ from the side. The two sensors were placed about $45 \mathrm{~mm}$ apart in order to have one sensor on the center of the specimen and one on the side, thus avoiding the bits of the barrel ripping the sensors, see Fig.8.

In Fig 97 the deformation of the sensors is expressed in micro strain $\mu \epsilon$, while in Fig. $9 \mathrm{~b}$ the temperatures are shown for the central and the side sensors. The temperature sensors seem to demonstrate that the water used for cooling the barrel did not have any visible effect in terms of deformations between core and skin of the core (thus producing a self-strain). A jump of some degrees of temperature was visible after 30 minutes of coring in the external part of the core due to an adjustment of the flow of cooling water. The external layer of the concrete tended to contract while the core expanded. At the end of the coring phase the specimens were left in the socket and the water was stopped (in the space left by the barrel there was no water because it escaped from the bottom immediately after the barrel was extracted). From

\footnotetext{
${ }^{3}$ Mechanical modelling of damage can be found, as an example, in [21, 22, 23, 40].
} 

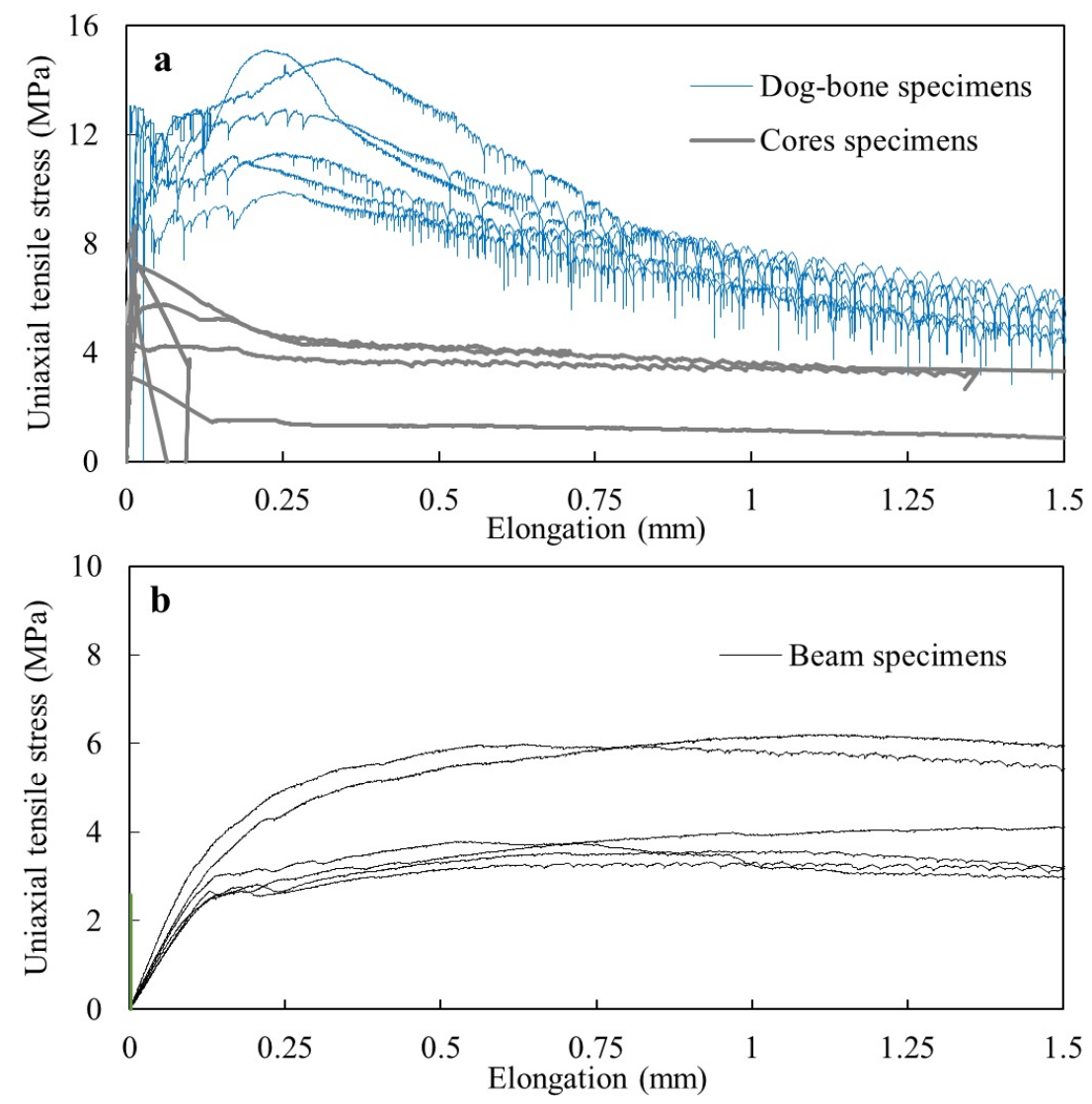

Figure 7: a) Standard uniaxial tensile tests on cores and dog-bone shaped specimens; b) Standard four-point bending flexural tests on beams cut from the full scale structure

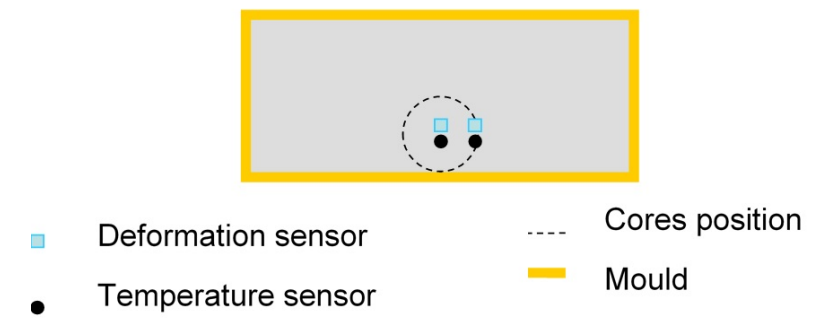

Figure 8: Position of sensors at the core position

that moment no further deformation was observed.

A possible explanation for the distortion of the section can be found in the release of a self-restrain or in the effect of the coring barrel. The eventual 


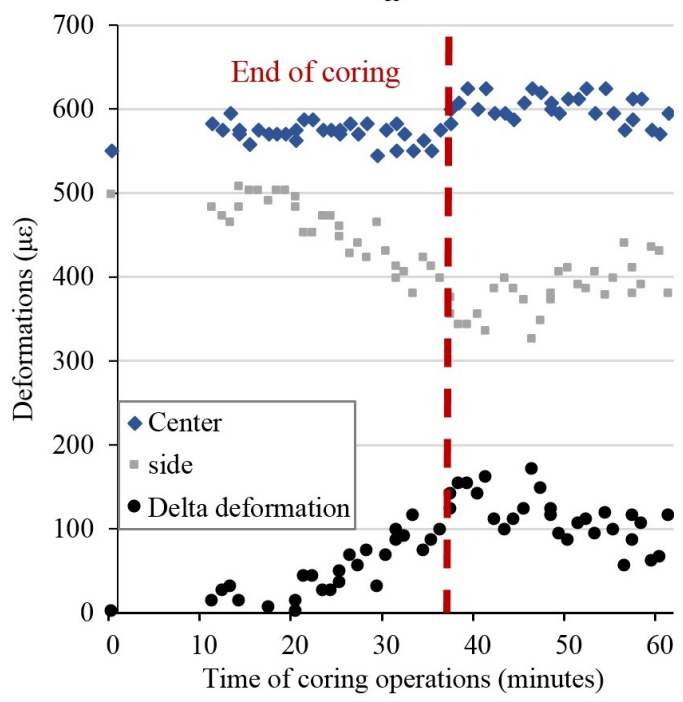

b

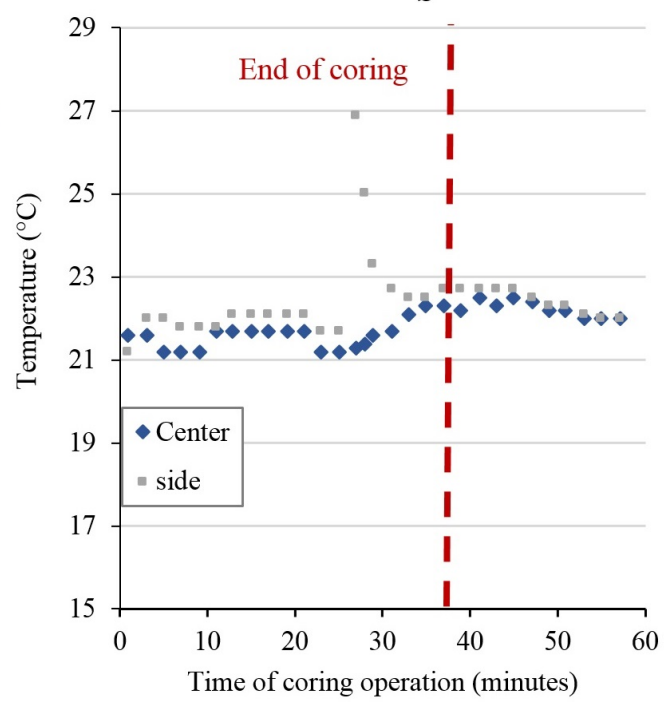

Figure 9: Deformation and temperature of the side and center sensors at the coring

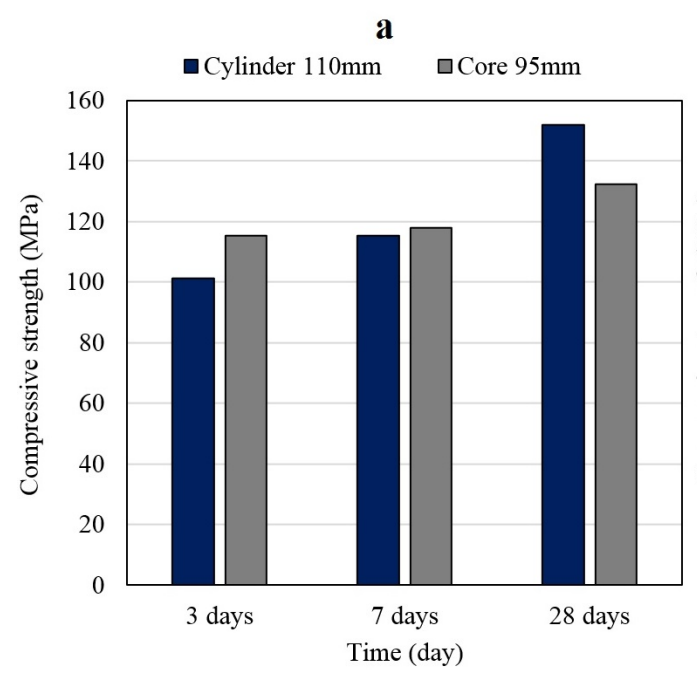

b

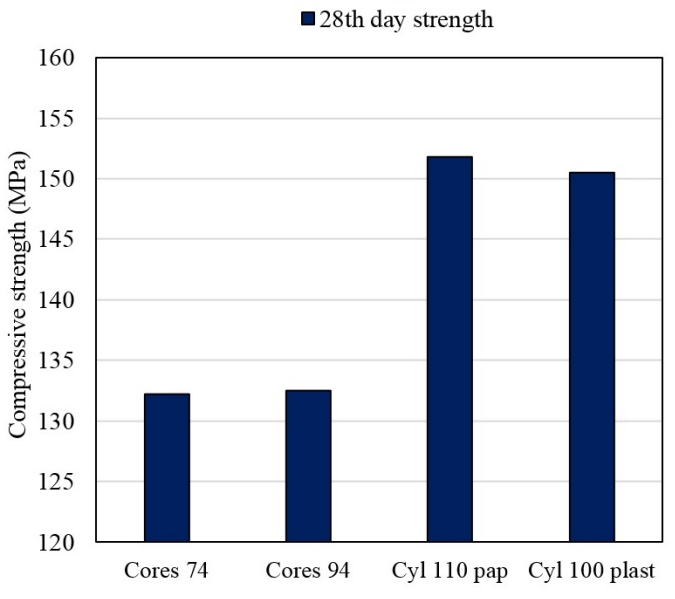

Figure 10: a) Compressive strength of cylinder and core specimens at 3,7 and 28 days; b) Compressive strength at 28 days of different size of specimens and molds types

water pressure on the side and the temperature of the cooling water did not seem to have any effect on this concrete. Compressive strength of cores with length-diameter ratio equal to 2 was tested. The cores were stronger 


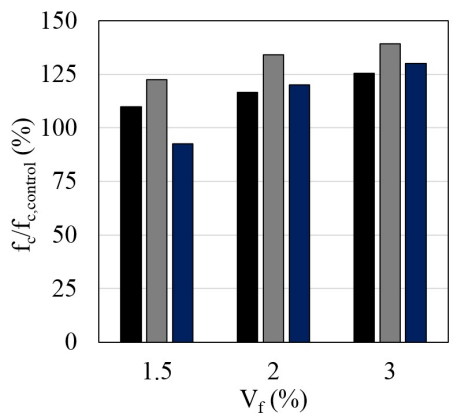
(Fig,10a). compared.

at early age (when the higher temperatures reached in the cored beam allow for a faster hydration) while at 28 days they test lower of more than $10 \%$, thus confirming that the strength retrogression occurred also in this case

In order to confirm that size of specimens and molds type were not an issue, four different types of specimens were tested for compressive strength at 28 days, i.e. two cores of different diameter (real diameter of the core were 94 and $74 \mathrm{~mm}$, length was the double of the diameter in both cases) and two cast cylinders (diameter 110 and $100 \mathrm{~mm}$, length double of the diameter, coated with paper box and plastic molds respectively). Fig $10 \mathrm{~b}$ shows that cores had similar strength in average and cast cylinder as well. This permitted to check if this potential source of error was having any effect. The average weight of all cores was $2510 \mathrm{~kg} / \mathrm{m}^{3}$ while the average weight of the cylinders was of about $2550 \mathrm{~kg} / \mathrm{m}^{3}$. This difference highlights that the concrete had the same degree of compaction in both cylinders and beam. It can therefore be affirmed that the extraction of cores in UHPFRC provoke a distortion of the section that can be quantified in about $100 \mu \epsilon$. This distortion is not due to the coring but by the extraction of the core from the structural element. However this distortion and the torsion promoted by the barrel coring the concrete might provoke enough microcracking in specimens of UHPFRC with low fibers content. This parameter should be taken carefully into account whenever the strengths of UHPFRC in the structure and in specimens are

Figure 11: Increase of mechanical strengths as steel fibers are added within the UHPC-A
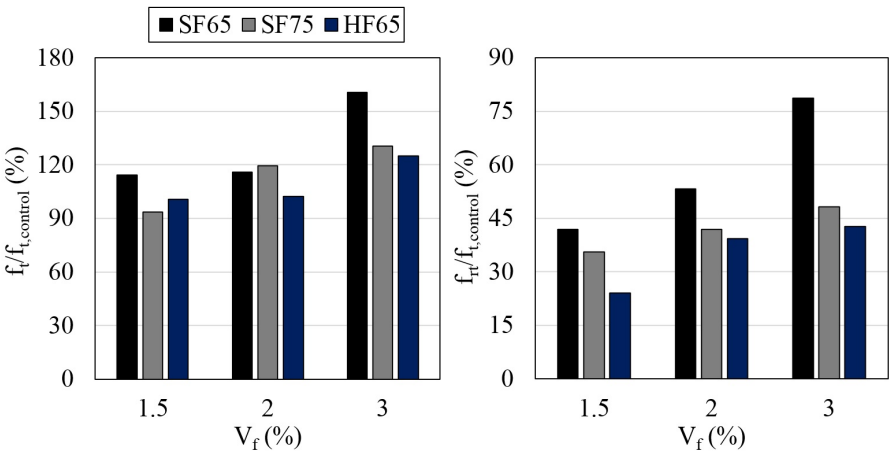


\begin{tabular}{lccccccccc}
\hline $\begin{array}{l}\text { UHPFRC } \\
\text { series }\end{array}$ & $\begin{array}{c}\text { Aver. } \\
(\mathrm{MPa})\end{array}$ & $\begin{array}{c}\text { COV } \\
(\%)\end{array}$ & $\begin{array}{c}\text { Rel. } \\
(\%)\end{array}$ & $\begin{array}{c}\text { Aver. } \\
(\mathrm{MPa})\end{array}$ & $\begin{array}{c}\text { COV } \\
(\%)\end{array}$ & $\begin{array}{c}\text { Rel. } \\
(\%)\end{array}$ & $\begin{array}{c}\text { Aver. } \\
(\mathrm{MPa})\end{array}$ & $\begin{array}{c}f_{r t} \\
\text { COV }\end{array}$ & $\begin{array}{c}\text { Rel. } \\
(\%)\end{array}$ \\
\hline A_Control & 103.95 & 6.23 & 100.00 & 6.10 & 8.54 & 100.00 & - & - & - \\
A_SF65_1.5 & 114.14 & 8.88 & 109.80 & 6.96 & 3.88 & 114.24 & 2.55 & 23.53 & 41.83 \\
A_SF65_2 & 121.30 & 5.47 & 116.68 & 7.07 & 11.17 & 116.05 & 3.24 & 20.06 & 53.15 \\
A_SF65_3 & 130.47 & 1.76 & 125.51 & 9.79 & 8.27 & 160.61 & 4.79 & 14.20 & 78.58 \\
A_SF75_1.5 & 127.41 & 8.25 & 122.57 & 5.71 & 13.41 & 93.70 & 2.17 & 15.67 & 35.60 \\
A_SF75_2 & 139.36 & 2.83 & 134.06 & 7.28 & 3.40 & 119.40 & 2.55 & 15.67 & 41.83 \\
A_SF75_3 & 144.84 & 1.27 & 139.33 & 7.95 & 1.85 & 130.35 & 2.94 & 17.69 & 48.23 \\
A_HF65_1.5 & 96.08 & 15.60 & 92.43 & 6.13 & 11.58 & 100.57 & 1.47 & 16.33 & 24.12 \\
A_HF65_2 & 124.92 & 2.79 & 120.17 & 6.23 & 4.65 & 102.21 & 2.39 & 17.57 & 39.21 \\
A_HF65_3 & 135.31 & 1.82 & 130.16 & 7.62 & 6.30 & 125.01 & 2.60 & 2.31 & 42.66 \\
B_Control & 167.32 & 4.28 & 100.00 & 9.17 & 12.07 & 100.00 & - & - & - \\
B_SF65_2.5 & 188.00 & 5.21 & 112.36 & 11.42 & 17.71 & 187.27 & 4.59 & 14.95 & 50.02 \\
\hline
\end{tabular}

Table 3: Results

\section{Extension of the previous predictive strength model}

The experimental results of UHPFRC-A and HPFRCC series listed in Table 3 and [35], respectively, were used to extend the predictive linear strength model for any HPFRC/UHPFRC, taking into account the matrix strength $(\mathrm{MPa})$, the size $(\mathrm{mm})$ and the dosage $(\%)$ of fibers as variables. A multi linear regression analysis with $95 \%$ confidence intervals, taking into account the experimental data was used to obtain the following relationships between matrix strength, fiber properties and compressive $\left(f_{c}\right)$, uniaxial $\left(f_{t}\right)$ and residual tensile $\left(f_{r t}\right)$ strengths of a given HPFRC/UHPFRC. From experimental results, the shape of fibers - straight and deformed - strongly affected the mechanical response of the composite, as also seen in [35, thus the model was adapted to both kinds of fibers.

The coefficients of correlation $R^{2}$ illustrated in Fig 12 are higher than those in [35, highlighting the strong influence of the matrix strength for a reliable prediction. Since matrix strength and fiber properties of the UHPFRCB full scale structural member were known, the model was used to predict its compressive and tensile strengths by using relationships in equations (1)-(6). Theoretical and experimental results of UHPFRC-B specimens were compared and drawn by red points. Once the compressive and tension strengths were predicted, it was possible to compute the flexural bending response by analytical approach. The Euler-Bernoulli hypothesis was adopted. A 

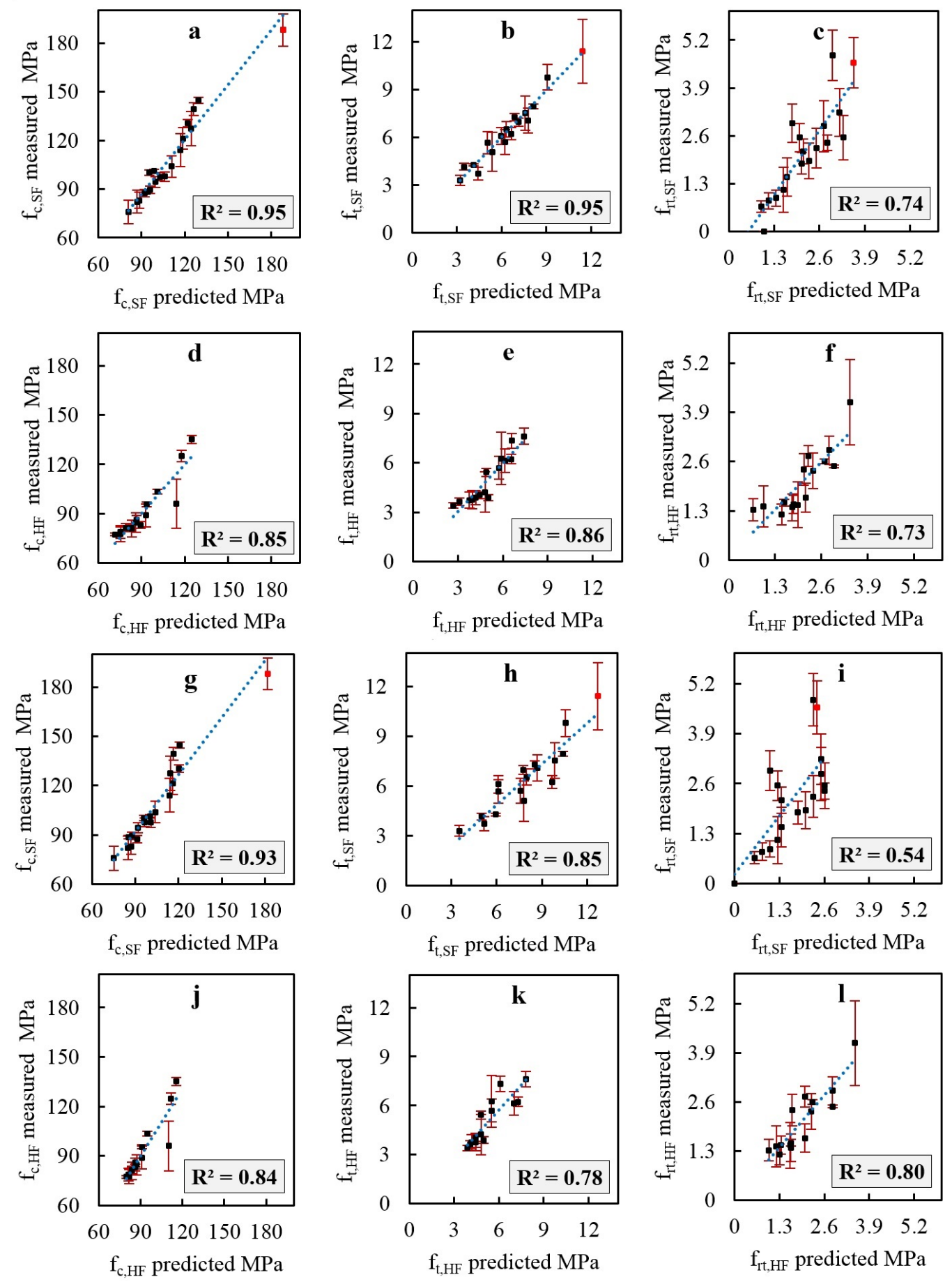

Figure 12: Correlation between measured (Table 3 and Table 3 in [35]) and predicted values of compressive, uniaxial and residual tensile strengths by the extended model (a-f) and the model in 35$](\mathrm{g}-\mathrm{l})$ 

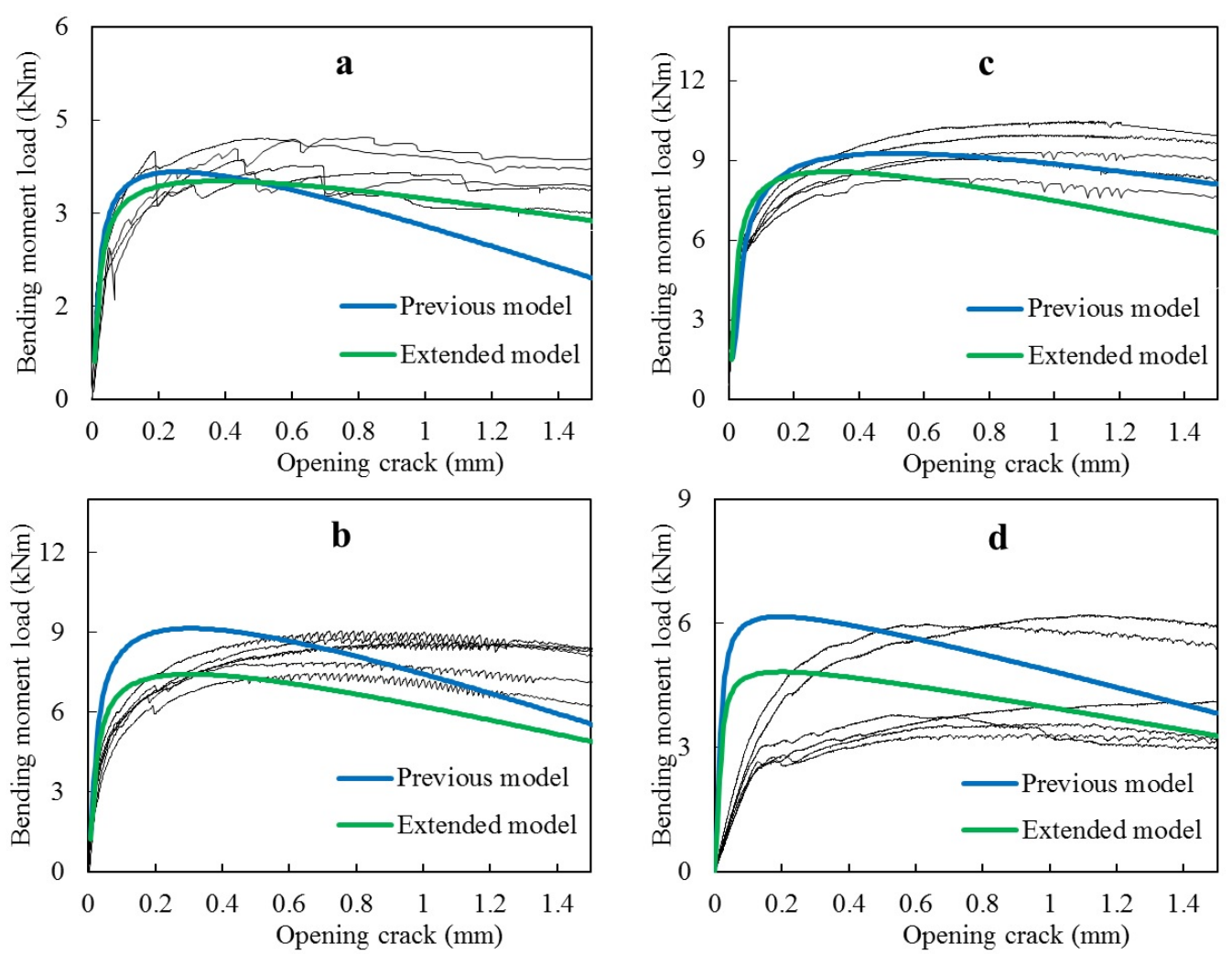

Figure 13: Correlation between experimental data of a, b, c ([36]), d (UHPFRC-B series) and theoretical results both of the extended model and previous model developed in [35]

parabola-rectangular stress-strain law in compression and bi-linear stressstrain laws in tension defined according to [52] and [57] were adopted in the model. $0.015 \%$ and $1.5 \%$ were assumed as elastic and ultimate strain tension values, as observed in Section 3.3. A numerical solver was used for computing the flexural response of the beam in terms of bending moment $(\mathrm{kNm})$ vs opening crack at the bottom ( $\mathrm{mm})$.

The comparison with experimental data was observed in Fig,13. It is worth noting that the prediction of flexural strength for the scale structural beam was reasonable due both to the not-preferential orientation of fibers within the cores and to the light damage of the latter during the coring and extraction, as claimed in 3.5. This phenomenon was not evidenced when theoretical results were compared to experimental data measured in [36], where a (HPFRCC), b (UHPFRC-I) and c (UHPFRC-2) series of six $150 \times 150 \times 600$ 
$\mathrm{mm}$ beams, cast and cured in lab conditions, showed a preferential orientation of fibers inside. For them the convergence with the extended model was much higher. Lower convergence is instead observed when the model in [35] was adopted for the prediction, thus confirming the need of a new extended model.

$$
f_{c, S F}=1.067 f_{c, \text { matrix }}+5.9562 l-393.2199 d_{e}+3.3258 V_{f}, R^{2}=0.92
$$

$$
f_{t, S F}=0.9788 f_{t, \text { matrix }}-0.9309 l+59.6367 d_{e}+1.2677 V_{f}, R^{2}=0.91
$$

$$
f_{r t, S F}=0.1644 f_{t, \text { matrix }}-0.0507 l+12.0514 d_{e}-0.2117 V_{f}, R^{2}=0.82
$$

$$
f_{c, H F}=1.3757 f_{c, \text { matrix }}-0.8456 l-17.7099 d_{e}+7.0429 V_{f}, R^{2}=0.90
$$

$$
f_{t, H F}=0.8526 f_{t, \text { matrix }}-0.0747 l-5.3867 d_{e}+0.8551 V_{f}, R^{2}=0.90
$$

$$
f_{r t, H F}=0.1163 f_{t, \text { matrix }}-0.0692 l-3.9987 d_{e}+0.5861 V_{f}, R^{2}=0.86 .
$$

\section{Conclusions}

The following main conclusions can be drawn:

- The influence of both matrix and steel fibers properties on the mechanical response of a given HPFRC/UHPFRC was investigated, confirming their key role as predictive parameters;

- A previous predictive strength model was extended in order to estimate the mechanical response in terms of compressive and tensile strengths for any HPFRC/UHPFRC, as matrix and fiber properties change, showing higher $R^{2}$ values. Furthermore, the new model was used to estimate the flexural bending response of a full scale structural beam and different marked UHPFRC beam specimens. A good agreement with the experimental results was evident. The regression 
analysis on more experimental data could be reduce the scatter of tensile strength results, typically high for the fiber reinforced mortars, in order to accurate the prediction of the related post-peak flexural response;

- A good agreement between the extended model and experimental data confirms not only that the model predicts well the mechanical behavior of any HPFRC/UHPFRC, but also that it can be used for detecting the optimal combination of matrix strength and fiber properties in order to identify the minimal dosage of fibers (or the minimal matrix strength) necessary to attain the strength requested in the field, reducing the costs of manufacturing as well;

- The fiber orientation strongly affects both the peak strength and the energy-absorbing capability of the post-cracking behavior, as seen by comparing the experimental results of cast and core specimens. In fact, in the cast specimens the molds shape encouraged a certain degree of fibers orientation, while in the cores drilled from the full scale structural beam fibers were randomly oriented;

- Another relevant effect of scatter in strength between cast and core specimens can be explained by considering the distortion of the section in the release of a self-restrain or in the effect of the coring barrel.

\section{Acknowledgments}

Authors gratefully acknowledge the financial support provided by HEIGVD. Financial support from the Italian Ministry of Education, University and Research (MIUR) in the framework of the Project PRIN "COAN 5.50.16.01" (code 2015JW9NJT) is gratefully acknowledged.

\section{References}

[1] An MZ, Zhang LJ, Yi QX. Size effect on compressive strength of reactive powder concrete. Journal of China University of Mining and Technology, 2008, 18 (2), pp. $279-282$.

[2] Barnett SJ, Lataste JF, Parry T, Millard SG, Soutsos MN. Assessment of fibre orientation in ultra high performance fibre reinforced concrete and 
its effect on flexural strength. Materials and Structures, 2010, 43 (7), pp. $1009-1023$.

[3] Boulekbache B, Hamrat M, Chemrouk M, Amziane S. Flowability of fibrereinforced concrete and its effect on the mechanical properties of the material. Construction and Building Materials 2010, 24 (9), pp. $1664-1671$.

[4] Chan YW, Chu SH. Effect of silica fume on steel fiber bond characteristics in reactive powder concrete. Cement and Concrete research, 2003, 34 (7), pp. $1167-1172$.

[5] Chen Y, Matalkah F, Weerasiri RR, Balachandra AM, Soroushian P. Dispersion of Fibers in Ultra-High-Performance Concrete. Concrete International, 2017, 39 (12) pp. $45-50$.

[6] Collepardi S, Coppola L, Troli R, Collepardi M. Mechanical Properties of Modified Reactive Powder Concrete. ACI Special Publication, 1997, 173, pp. $1-22$.

[7] Dezi L, Menditto G, Tarantino AM. Homogeneous structures subjected to successive structural system changes. ASCE Journal of Engineering Mechanics, 116(8), 1990, 1723-1732.

[8] Dezi L, Tarantino AM. Time dependent analysis of concrete structures with variable structural system. ACI Materials Journal, 88(3), 1991, 320324.

[9] Dezi L, Menditto G, Tarantino AM. Viscoelastic heterogeneous structures with variable structural system. ASCE Journal of Engineering Mechanics, $119(2), 1993$, pp. 238-250

[10] Eldin HKS, Mohamed HA, Khater M. Mechanical Properties of UltraHigh Performance Fiber Reinforced Concrete. Internation Journal of Engineering and Innovative Technology, 2014, 4 (4), pp.

[11] Falope FO, Lanzoni L, Tarantino AM. Modified hinged beam test on steel fabric reinforced cementitious matrix (SFRCM). Composites Part B: Engineering, 2018, 146, pp. 232-243.

[12] Falope FO, Lanzoni L, Tarantino AM. Double lap shear test on steel fabric reinforced cementitious matrix (SFRCM). Composite Structures, 2018, 201, pp. 503-513. 
[13] Ferrara L. High performance fiber reinforced self-compacting concrete (HPFRSCC): a smart material for high end engineering applications. In: $3^{\text {rd }}$ International workshop on heterogeneous architectures and computing, Madrid, 2012, pp. $323-334$.

[14] Fujikake K, Senga T, Ueda N, Ohno T, Katagiri M. Effects of Strain Rate on Tensile Behavior of Reactive Powder Concrete. Journal of Advanced Concrete Technology, 2006, 4 (1), pp. $79-84$.

[15] Fujikake K, Uebayashi K, Ohno T, Shimoyama Y, Katagiri M. Dynamic Properties of Steel Fiber Reinforced Mortar Under High-Rates of Loadings And Triaxial Stress States. In: Proceedings of the 7th International Conference on Structures under Shock and Impact VII, Montreal, 2008, pp. $437-446$.

[16] Habel K, Viviani M, Denari E, Brhwiler E. Development of the Mechanical Properties of an Ultra-High Performance Fiber Reinforced Concrete (UHPFRC). Cement and Concrete research, 2006, 36 (7), pp. 1362-1370.

[17] Kang ST, Lee Y, Park YD, Kim JK. Tensile fracture properties of an Ultra High Performance Fiber Reinforced Concrete (UHPFRC) with steel fiber. Composite Structures, 2010, 92 (1), pp. $61-71$.

[18] Kazemi S, Lubell AS. Influence of Specimen Size and Fiber Content on Mechanical Properties of Ultra-High-Performance Fiber-Reinforced Concrete. ACI Material Journal, 2012, 109 (6), pp. 675 - 684.

[19] Koh KT, Park JJ, Ryu GS, Kang ST. Effect of the Compressive Strength of Ultra-High Strength Steel Fiber Reinforced Cementitious Composites on Curing Method. KSCE Journal of Civil Engineers, 2007, 27 (3A), pp. $427-$ 432.

[20] Lanzoni L, Soragni M, Tarantino AM, Viviani M. Concrete beams stiffened by polymer-based mortar layers: experimental investigation and modelling. Construction and Building Materials 105 (2016) 321-335.

[21] Lanzoni L, Tarantino AM. Damaged hyperelastic membranes. Int. J. NonLinear Mech. 60 (2014) 9-22. 
[22] Lanzoni L, Tarantino AM. Equilibrium configurations and stability of a damaged body under uniaxial tractions. ZAMP Zeitsc. Angew. Math. Phys. 66(1) (2015) 171-190.

[23] Lanzoni L, Tarantino AM. A simple nonlinear model to simulate the localized necking and neck propagation. Int. J. NonLinear Mech. 84 (2016) 94-104.

[24] Li VC. Strategies for High Performance Fiber Reinforced Cementitious Composites Development. Fiber reinforced concrete: from theory to practice. In: Proceedings of the North American/European Workshop on Advanced Fiber Reinforced Concrete, Bergamo, Italy, 2004. pp. 93 - 98.

[25] Ma J, Orgass M, Dehn F, Schmidt D, Tue NV. Comparative Investigations on Ultra-High Performance Concrete with and without Coarse Aggregates. In: Proceedings of the International Symposium on Ultra High Performance Concrete, Kassel, Germany, 2004, pp. 205 - 212.

[26] Martinie L, Rouseel N. Simple tools for fiber orientation prediction in industrial practice. Cement and Concrete Research, 2011, 41 (10), pp. $993-1000$.

[27] Naaman AE. High Performance Fiber Reinforced Cement Composites. In: Caijun S, Mo YL (eds) High-Performance Construction Materials. Science and Applications, 2008, pp. $91-153$.

[28] Naaman AE, Reinhardt HW. Proposed classification of HPFRC composites based on their tensile response. Materials and Structures, 2006, 39 (5), pp. $547-555$.

[29] Nguyen DL, Kim DJ, Ryu GS, Koh KT. Size effect on flexural behavior of ultra-high-performance hybrid fiber-reinforced concrete. Composites Part B: Engineering, 2013, 45 (1), pp. $1104-1116$.

[30] Nobili A, Falope FO. Impregnated carbon fabric-reinforced cementitious matrix composite for rehabilitation of the Finale Emilia hospital roofs: case study. Journal of Composites for Construction. 2017, 21 (4), pp.05017001.

[31] Orgass M, Klug Y. Fibre Reinforced Ultra-High Strength Concretes. In: Proceedings of the International Symposium on Ultra High Performance Concrete, Kassel, Germany, 2004, pp. $637-647$. 
[32] Prabha SL, Dattatreya JK, Neelamegam M, Seshagirirao MV. Study on stress-strain properties of reactive powder concrete under uniaxial compression. Internation Journal of Engineering, Science and Technology, 2010, 2, 11 , pp. $6408-6416$.

[33] Ramadoss P, Nagamani K. Tensile Strength and Durability Characteristics of High-Performance Fiber Reinforced Concrete. The Arabian Journal for Science and Engineering, 2006, 33 (2B), pp.307 - 319.

[34] Rougeau P, Borys B. Ultra High Performance Concrete with ultrafine particles other than silica fume. In: Proceedings of the International Symposium on Ultra High Performance Concrete, Kassel, Germany, 2004, pp. $213-226$.

[35] Savino V, Lanzoni L, Tarantino AM, Viviani M. Simple and effective models to predict the compressive and tensile strength of HPFRC as the steel fiber content and type change. Composites Part B, 2018, 137, pp. $153-162$.

[36] Savino V, Lanzoni L, Tarantino AM, Viviani M. Tensile constitutive behavior of high and ultra-high performance fibre-reinforced-concretes. Construction and Building Materials, 2018, 186, pp. 525 - 536 .

[37] Schmidt M, Fehling E. Ultra-High-Performance Concrete: Research, Development and Application in Europe. ACI Material Journal, 2005, 228, pp. $51-78$.

[38] Signorini C, Nobili A, Falope FO. Mechanical performance and crack pattern analysis of aged Carbon Fabric Cementitious Matrix (CFRCM) composites. Composite Structures, 2018, 202, pp. $1114-1120$.

[39] Sumathi A, Saravana RMK. Study on the Strength and Durability Characteristics of High Strength Concrete with Steel Fibers. International Journal of ChemTech Research, 2015, 8, (1), pp. $241-248$.

[40] Tarantino AM. Equilibrium paths of a hyperelastic body under progressive damage - Journal of Elasticity, 114, 2014, pp. 225-250.

[41] Van Tuan V, Ye G, Van Breugel K, Fraaij AL, Dai BD. The study of using rice husk ash to produce ultra high performance concrete. Construction and Building Materials, 2011, 25 (4), pp. 2030 - 2035. 
[42] Wille K, Kim DJ, Naaman AE. Strain-hardening UHP-FRC with low fiber contents. Materials and Structures, 2011, 44 (3), pp. 583 - 598.

[43] Wille K, Naaman AE. Pullout Behavior of High-Strength Steel Fibers Embedded in Ultra-High-Performance Concrete. ACI Material Journal, 2012, 109 (4) pp. $479-488$.

[44] Yang IH, Joh C, Kim BS. Structural behavior of ultra high performance concrete beams subjected to bending Engineering Structures, 2010, 32 (11), pp. $3478-3487$.

[45] Yazıcı Ş, İnan G, Tabak V. Effect of aspect ratio and volume fraction of steel fiber on the mechanical properties of SFRC. Construction Building Materials, 2007, 21, pp. $1250-1253$.

[46] Yazıcı Ş H, Yardımcı MY, Aydin S, Karabulut AŞ. Mechanical properties of reactive powder concrete containing mineral admixtures under different curing regimes. Construction and Building Materials, 2009, 23 (3) pp. $1223-1231$.

[47] Yoo DY, Kang ST, Yoon YS. Effect of fiber length and placement method on flexural behavior, tension-softening curve, and fiber distribution characteristics of UHPFRC. Construction and Building Materials, 2014, 64, pp. $67-81$.

[48] Yoo DY, Lee JH, Yoon YS. Effect of fiber content on mechanical and fracture properties of ultra high performance fiber reinforced cementitious composites. Composite Structures, 2013, 106, pp. $742-753$.

[49] Yoo DY, Yoon YS. Structural performance of ultra-high-performance concrete beams with different steel fibers. Engineering Structures, 2015, 102, pp. $409-423$.

[50] Yunsheng Z, Wei S, Sifeng L, Chujie J, Jianzhong L. Preparation of C200 green reactive powder concrete and its static-dynamic behaviors. Cement and Concrete Composites, 2008, 30 (9), pp. $831-838$.

[51] CNR-DT 204. Guidelines for design, construction and production control of fiber reinforced concrete structures. National Research Council of Italy. 2006 . 
[52] EN $1992-1-1$. Design of concrete structures. General rules and rules for buildings. 2004.

[53] fib. Structural Concrete. Textbook on behaviour, design and performance. CEB-FIP, 2009, 52.

[54] JSCE. Recommendations for Design and Construction of Ultra-High Strength Fiber-Reinforced Concrete Structures. Japan Society of Civil Engineering, 2006.

[55] PrSIA 2052. Béton fibré ultra-performant (BFUP)-Matériaux, dimensionnement et exécution. $2014-04$.

[56] SETRA-AFGC. Ultra High Performance Fibre Reinforced Concrete. Interim Reccomendations, 2002.

[57] UNI 11188. Steel fibres reinforced concrete structural elements Design, execution and control. 2007.

[58] UNI EN 12390 - 2. Testing hardened concrete - Making and curing specimens for strength tests, 2009.

[59] UNI EN 12390 - 3. Testing hardened concrete - Compressive strength of test specimens. 2003.

[60] UNI EN 12390 - 7. Testing hardened concrete - Density of hardened concrete. 2000. 


\section{List of Figures}

1 Types of steel fibers investigated: a) SF65; b) SF75; c) HF65;

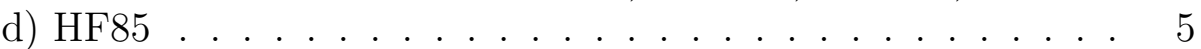

2 Geometrical dimensions (mm) of the standard dog-bone shaped

3 Geometry of the full scale beam and position of the drilled specimens (B: beams, C: cores) . . . . . . . . . . 6

$4 \quad$ Phenomenon of fiber balling occurred in HF85 series . . . . . 8

5 (a)Comparison of the specimens density; (b)Visual orientation and distribution of fibers in series a) SF65-D, b) SF65-C, c) SF75-D, d) SF75-C, e) HF65-D, f) HF65-C (b)| . . . . . . . . 8

6 Parameters of the uniaxial tensile behavior recorded from tested dog-bone shaped specimens . . . . . . . . . . . . . . . 10

$7 \quad$ a) Standard uniaxial tensile tests on cores and dog-bone shaped specimens; b) Standard four-point bending flexural tests on beams cut from the full scale structure . . . . . . . . . . . . 12

$8 \quad$ Position of sensors at the core position . . . . . . . . . . . . . 12

9 Deformation and temperature of the side and center sensors at the coring. . . . . . . . . . . . . . . . . . . . 13

10 a) Compressive strength of cylinder and core specimens at 3 , 7 and 28 days; b) Compressive strength at 28 days of different size of specimens and molds types . . . . . . . . . . . . . 13

11 Increase of mechanical strengths as steel fibers are added within the UHPC-A . . . . . . . . . . . . . . . . . . . . 14

12 Correlation between measured (Table 3 and Table 3 in [35]) and predicted values of compressive, uniaxial and residual tensile strengths by the extended model (a-f) and the model in [35] $(\mathrm{g}-\mathrm{l}) \ldots \ldots \ldots \ldots \ldots$

13 Correlation between experimental data of a, b, c $([36])$, d (UHPFRC-B series) and theoretical results both of the extended model and previous model developed in [35] . . . . . . 17 